\title{
Analysis of the Sleep Disorders in Students Under the Effect of Computer Games and Video Films
}

\author{
Kira Mezianaya ${ }^{1,}$, , Konstantin Karaneuski ${ }^{2}$, Konstantin Yashin ${ }^{2}$, Anatoly Davidovski \\ ${ }^{1}$ The Centre for Children's Correctional and Development Training and Rehabilitation, Minsk, Belarus \\ ${ }^{2}$ Chair of Engineering Psychology and Ergonomics, Faculty of Computer Design, Belarusian State University of Informatics and \\ Radioelectronics, Minsk, Belarus
}

Email address:

kira.m_2010@mail.ru (K. Mezianaya)

${ }^{*}$ Corresponding author

\section{To cite this article:}

Kira Mezianaya, Konstantin Karaneuski, Konstantin Yashin, Anatoly Davidovski. Analysis of the Sleep Disorders in Students Under the Effect of Computer Games and Video Films. American Journal of Psychiatry and Neuroscience. Vol. 6, No. 3, 2018, pp. 67-71.

doi: 10.11648/j.ajpn.20180603.13

Received: July 14, 2018; Accepted: August 1, 2018; Published: September 1, 2018

\begin{abstract}
Introduction and wide use of information technologies in all spheres of human life including for the purpose of entertainment has led to the emergence and spread of various types of Internet addiction. Numerous studies have established the effect of the nature of activity in the virtual world on the state of the human mental condition. In our research was conducted analysis of the sleep disorders in technical university students, who use computer games and video films for recreation and entertainment. We have researched in the sleep disorder mechanisms in technical university students, who use computer games and video films for recreation and entertainment. The authors of the article K. N. Meziyanaya, K. D. Yashin, K. M. Karaneuski developed the questionnaire "Method of Screening Diagnostics of Computer Addiction and its Influence on Physical and Mental Health" to study of formation of sleep disorders [1]. Interviews with 142 2nd to 5 th year students studying in one of the technical universities of Minsk city were conducted in order to study the formation of sleep disorders under the influence of the computer media environment: males - 119 (84.4\%), females $-23(16.2 \%)$. The average age of respondents was $19.7( \pm 1.5)$ years. The average duration of the virtual world use was $9( \pm 2)$ years. It is established that 101 students $(71.1 \%$ of the number of respondents) are forced to wake up from fear and anxiety. The statistical relationship is shown between the symptom of sleep disturbance: they say in a dream "I just dream it" and the symptom: duration of stay in the virtual world 40 or more hours per week. $\chi^{2}$ criterion $=5.63 ; \mathrm{p}=0.05$. The relationship between combining computer games with watching movies and waking up from fear and anxiety is found, $\chi^{2}$ criterion $=4.38, p=0.05$. The findings suggest that the continued use of computer games in combination with viewing video films contributes to the development of malfunction of the organization and maintenance of sleep. The results testify to the correlation between a sleep disorder and a prolonged stay in the virtual world, which can contribute to predicting the formation of anxiety disorders.
\end{abstract}

Keywords: Sleep Disorders, Computer Games, Movies, Anxiety Disorders

\section{Introduction}

Wide use by young people of modern information technologies for recreation and entertainment calls for an active study of the influence of computer games and other Internet resources on the mental sphere of adolescents and youths $[2,3]$. Modern multi-user computer games and social networks form a new environment for communicative and entertaining activities [4]. The studies by the scientists have established personal and behavioral deviations characteristic of the persons with Internet addiction [5-8]. The need further studies the problems of influence of the virtual world on the emotions and many scientists recognize volition of users [9, 10]. Emotional and volitional disorders precede the development of psychopathological symptoms and behavioral disorder in users. One of the most important symptoms that indicate the appearance of abnormalities in the neuropsychic sphere is personality anxiety disorders (PAD). It is demonstrated that sleep disorders are an 
important predictor of anxiety formation [11, 12]. Epidemiological studies have shown that in case of PAD sleep disorders are detected in 44 to $81 \%$ of cases; in $68 \%$ of cases they occur simultaneously with the development of anxiety, whereas in $15 \%$ such disorders appear soon after the onset of PAD [13]. Such violations are often leading, and sometimes they are the only manifestations of PAD.

The study of sleep quality in young adults found that half of the respondents aged 15 to 25 years (n-1115) have disturbances in night sleep. The author points out that one of the reasons is the use of computer games for the purpose of entertainment [14]. It is worthy of note that the sleep disorders in users of computer games have been studied insufficiently.

The need to study the influence of computer games on the development of insomnia at schoolchildren and students as a predictor of the formation of PAD is one of the tasks of research in the field of computer addiction.

The work is supported by the grant of the Ministry of Education of the Republic of Belarus, GBTs $15-3088 \S$ 52.999.00.

\subsection{The Study Objective}

Research in the sleep disorder mechanisms in technical university students, who use computer games and video films for recreation and entertainment

\subsection{The Study Tasks}

To explore the duration of students' stay in computer media for recreation and entertainment. To study the effect of computer games and video films on the formation of sleep disorders.

\subsection{The Study Object}

Students studying technical specialties.

\subsection{The Study Subject}

Analysis of the structure of the virtual world types used by students for entertainment and their effect on the formation of sleep disorders.

\section{Materials and Methods}

In those, study took participate 142 students from 2 nd to 5 th year from one of the technical universities of Minsk were surveyed: males - 119 (84.4\%), females - 23 (16.2\%). The average age of the respondents was $19( \pm 1.5)$ years. The average duration of using the virtual world was 9 years. The anonymous questionnaire survey was conducted in the second term of the academic year (in April) by a method of continuous interviewing of students before a lecture or a practical session. All respondents gave informed consent to participate in the study. The following questionnaire was developed for the study: «Method of Screening Diagnostics of Computer Addiction and Its Effect on Mental Health». No. 20140678 dated August 30, 2015, authors: Mezyanaya K,
Yashin K, Karaneuski K. [15]. The internal consistency between the characteristics in the questionnaire was verified by calculating the Cronbach $\alpha$ coefficient $=0.69$. In order to analyze the stability of the data obtained from this questionnaire, ten students were surveyed twice, randomly selected, at intervals of 30 days. The Mann-Whitney criterion was determined for two independent samples. The differences in the attribute level among the compared groups are statistically insignificant, which makes it possible to draw a conclusion about sufficient retest reliability of the questionnaire [1].

Its six types analyzed preferences for the use of the virtual world: computer games, social networks, Internet surfing, films, including television series and video reels; cybersex; gambling for entertainment. The classification used in the CIS countries [6]. The box "Other Purpose" was included for accounting educational and work activities. It was allowed to mark several answers. To analyze the time devoted to computer activity, a period of 168 hours (7 days) was taken, with gradation in three intervals: from 1 to 24 hours, 25 to 39 hours, 40 hours or more. The analysis of the length of time spent at the computer during the day was carried out in three intervals: up to 3 hours, 3-5 hours, 6 hours or more. To characterize sleep disorders, the questionnaire included three questions: about the awakening from fear and anxiety, awakening from unpleasant dreams; about the presence of a statement in a dream that it is not happening to this person: they say to themselves in a dream, "I just dream it". The structure of sleep was analyzed for the presence of the following in dreams: continuation of the computer game, presence of the hero from the game and repetition of the plot [10].

Statistical analysis of the data obtained was carried out using contingency tables and calculating $\chi^{2}$ of the Pearson criterion. To establish the measure of the relationship between the symptoms, the coefficient $\varphi$ is used, where 0 is a weak relation, and 1 is a strong one. Pearson's $\chi 2$ criterion (with a significance level $\alpha=0.05$ ) was calculated for four symptoms: combining computer games with watching movies, parasomnic disorder: they say to themselves in a dream: "I just dream it"; waking up from fear and anxiety; and using the virtual world for more than 40 hours in week. Variations were considered statistically significant at $p<0.05$ [16]. The results of the study were processed using Microsoft Office Excel 2010 and the STATISTICA 10.0 package (for Windows).

\section{The Study Results}

An important symptom of the loss of control over the time of using the internet and computer games is the duration of stay in the virtual world. Scientists recognize as a reliable symptom of computer addiction the duration of a regular stay in the virtual space for the purpose of simple pastime, without a work program, over 38 hours during the week [17].

We analyzed the duration of the respondents' stay in the virtual world during the week (Figure 1). 


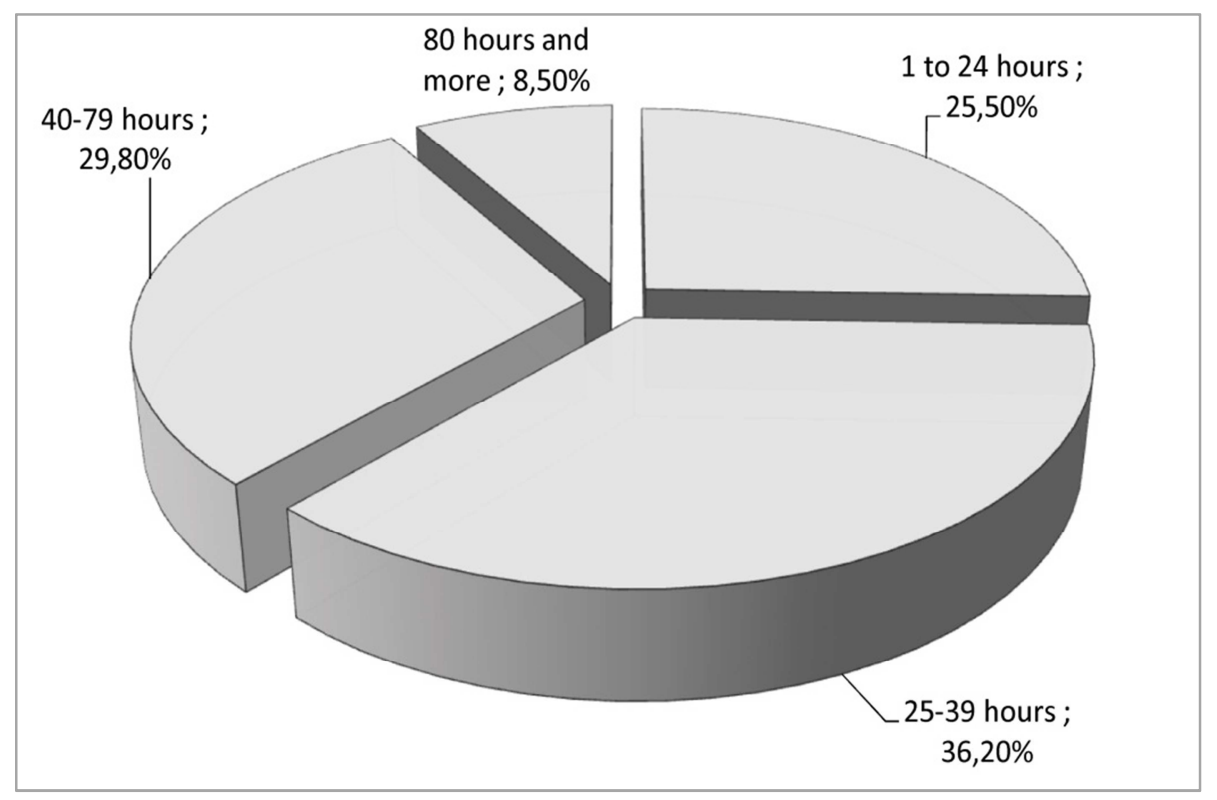

Figure 1. Distribution of the virtual world forms per the frequency of use by respondents.

As can be seen in Figure 1, a significant proportion of students, 51 persons $(38.3 \%)$, spend 40 or more hours a week in the virtual world. In 12 persons $(8.5 \%)$, computer enthusiasm acquired a dipsosis nature: they either have not used the computer at all or have spent up to seven days continuously in the virtual world, which may indicate a severe form of computer addiction. Such persistent use of games and the internet inevitably affects the mechanisms of organization and maintenance of sleep. Consequently, sleep disorders of parasomniac type - sleep disorders of psychoemotional nature - were detected in 31 persons $(21.8 \%)$ of the total number of those surveyed: they say to themselves in a dream, "I just dream it!" The negative impact of the virtual game world on the psycho-emotional state of students is also confirmed by the fact that 17 persons in this group used to wake up from an attack of anxiety in the night.

A statistical relationship is defined between the symptom "They say to themselves in a dream 'I just dream it" and the symptom "Duration of stay in the virtual world is 40 hours or more per week."

It is established that 115 students $(82.4 \%)$ use several types of virtual world for entertainment and study: two types -54 persons $(38 \%)$, three types -48 persons $(33.8 \%)$, four types - 15 persons $(10.6 \%)$, and two students used all available resources. Figure 2 shows distribution of virtual world types according to the number of students using them.

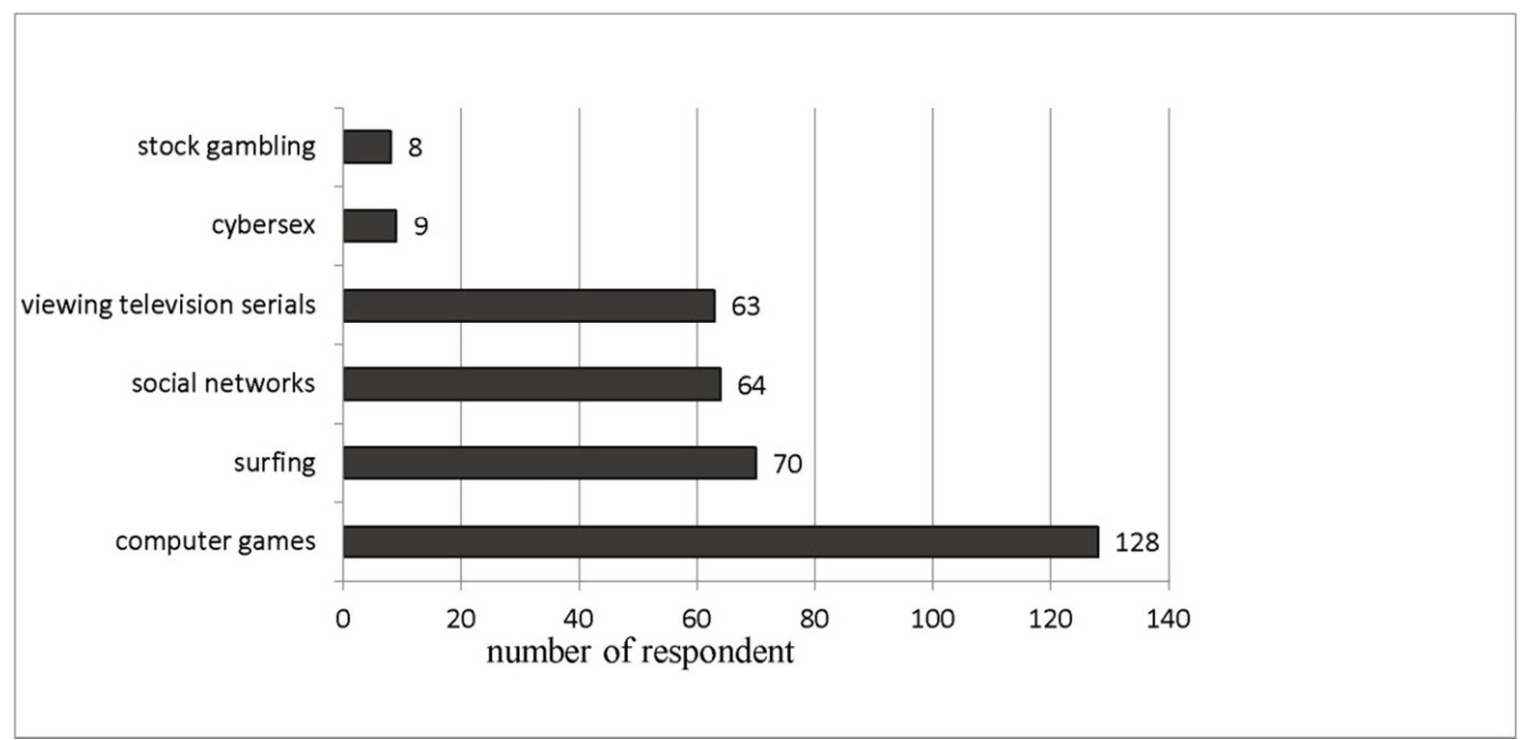

Figure 2. Distribution of the virtual world types by the number of users among respondents.

As can be seen in Figure. 2, 128 respondents use computer games. Structural analysis of use of the time outside studies, which students spend in the virtual world (out of $100 \%$ of the total time spent at the computer) showed that the activity 
associated with study and work amounts to about $15 \%$ of the time, while an average of $55 \%$ is devoted to games. At the same time, $46.8 \%$ of respondents devote to games $80-90 \%$ of the time. Which limits their social activity in the real world.

The analysis of preferences for the genres of computer games used showed that multiuser role-playing online games (World of Warcraft, Dota, World of Tanks, etc.) prevail in the student's compendium of games. As a rule, their plot is connected with fighting and using violence, although there are a number of such peaceful games. However, a significant portion of the respondents, 81 people (57\%), and use genres are mainly based on violence (military strategies, horror games, combat simulations). Emotionally charged experiences during the game process contribute to fixing plots and images from the virtual world in the memory and their subsequent appearance in dreams.

Table 1. The level of statistical correlation between staying in the virtual world 40 and more hours per week and intrasomnia disorder (They say to themselves in a dream: "I just dream it").

\begin{tabular}{lll}
\hline \multirow{2}{*}{ Type of sleep disorder } & \multicolumn{3}{l}{ Duration of using the virtual world 40 and more hours per week } \\
\cline { 2 - 3 } & Pearson's criterion $\chi^{2}$ & Coefficient $\varphi$ \\
\hline They say to themselves in a dream "I just dream it!" & 5.63 & 0,25 \\
\hline
\end{tabular}

The study results allow us to conclude that there is a connection between a sleep disorder and a prolonged stay in the virtual world, which may be one of the criteria for predicting the formation of an anxiety disorder in users. As the results of the analysis showed, 77 students (54.2\%) involuntarily wake up from fear and anxiety.

The influence of the virtual world types on psychoemotional sphere of users is studied. A special role of combining computer games with watching films for the students waking up from fear and anxiety is established. The statistical relationship between the following symptoms is determined: awakening from fear and anxiety and combining computer games with watching movies (Table 2).

Table 2. Statistical relationship between awakening from fear and anxiety and combining computer games with watching movies.

\begin{tabular}{lll}
\hline \multirow{2}{*}{ Kind of sleep disorders } & \multicolumn{3}{l}{ Combining computer games with watching movies } \\
\cline { 2 - 3 } & Pearson's criterion $\boldsymbol{\chi}^{2}$ & Coefficient $\boldsymbol{\varphi}$ \\
\hline Awakening from fear and anxiety & 4.38 & 0.36 \\
\hline
\end{tabular}

In general, fear, anxiety and/or nightmares during sleep are the cause of awakening in 101 respondents $(71.1 \%)$.

\section{Conclusion}

As the results of the conducted research show, the use of the internet and computer games has acquired the nature of preferential entertainment among the students who are trained in technical specialties. Prolonged use of the computer media environment is revealed in $35.9 \%$ of respondents, they spend 40 or more hours a week in the virtual world. The analysis of the structure of the use of free time which students spend in the virtual world (out of $100 \%$ of the time at the computer) showed that activity related to study and work takes no more than $15 \%$ of the time, while games are dedicated to about $55 \%$.

Students involved in computer games often experience the same emotions in a dream as in a computer game or while watching a movie, since the decay of biological excitement requires certain time and conditions. The perception of danger in the process story-driven game adventures causes euphoria and excitement at the first stage. At the same time, the high level of negative emotions induced by the virtual world makes the basis for anxiety. In addition, the need for leadership formed in the process of achieving success in the game, on the one hand, and the impossibility of implementing this in real life, on the other, are a prerequisite for the development of psychosomatic pathology owing to violations in the emotional and volitional sphere of a personality. In this connection parasomnic disorders are formed, in which symptoms of a sleep talking type may occur: they say to themselves in a dream, "I just dream it". The relationship between the formation of such sleep disorders like awakening from fear and anxiety and the use of computer games in combination with watching movies is also established.

The sleep disorders revealed by us in students indicate the need for extensive studies of neuropsychological and psychodynamic mechanisms of the influence of various virtual world types on the human mental state with a view to preventing health disorders among young people and adolescents who are the major part of the population using information and computer technologies.

\section{References}

[1] Mezianaya K, Yashin K, Karaneuskii K. Diagnostic questionnaire for determination of the signs of computer addiction and its impact on health. Jour. European science review. 2017. №5-6. P. 61-67.

[2] Yashin K, Mezianaya K, Zalivaka S, Karaneuski K. Effect of Virtual World on the Students' Personality and Health. Information Technologies. No. 10, 2013, pp. 50-55.

[3] Seyyed S, Mohammad R, Fereshte J, Mehdi E. The effect of psychiatric symptoms on the internet addiction disorder in Isfahan's University students. Journal Research Medical Science. Vol. 16, No. 6, 2011, pp. 793-800.

[4] Laffan D, Greaney J, Barton H, Kaye L. The relationships between the structural video game characteristics, video game engagement and happiness among individuals who play video games. Computer. Hum. Behav. Vol. 65, No. 5, 2016, pp. 44-9. 
[5] Avetisova A. Specific Psychological Features of Computer Game Players. Psychology Journal of the Higher Economic School. Vol. 8, No. 4, 2011, pp. 35-58.

[6] Egorov A. Non-chemical Dependencies. SPb: Speech, 2007.

[7] Koronczai B, Urbán R, Kökönyei Paksi. et al. Confirmation of the Three-Factor Model of Problematic Internet Use on OffLine Adolescent and Adult Samples. Cyberpsychol Behav Soc Netw. Vol. 14, No. 11, 2011, pp. 657-664.

[8] Palaus M, Marron E, Viejo-Sobera R, Neural. Basis of Video Gaming: A Systematic Review. Journal of Frontiers in Human Neuroscience. Vol. 11, No. 5, 2017, pp. 1-40.

[9] Goldsmith T, Keck P, Khosla U, McElroy S. Psychiatric features of individuals with problematic internet use. Journal of Affective Disorders. Vol. 57, No. 3, 2000, pp. 267-72.

[10] Davidovsky A, Mezianaya K, Yashin K, Karaneuski K. Influence of Computer Games on the Sleep Quality and the Nature of Dreams in Students. European Science Review. No. 6, 2015, pp. 130-133.

[11] Remizevich R. On Reciprocal Interrelations of Anxiety Disorders and Sleep Disorders. Topical Somnology Problems. Vol. 4, No. 5, 2011, pp. 58-62.
[12] Strygin K, Yumatov E, Levin Ya. Correlation of Personal Features and Parameters of Human Night Sleep. Paper presented for the National Society for Somnology and Sleep Medicine at 8th All-Russian Conference "Actual Problems of Somnology".

[13] Dalbudak E, Evren C, Aldemir S, Coskun K. et al. Relationship of internet addiction severity with depression, anxiety and alexithymia, temperament and character in university students. Cyberpsychology Behavior Social Networking. Vol. 16, No. 4, 2013, pp. 272-278.

[14] Golencov A, Ivanova I, Kuklina K. Epidemiology of sleep disorders in medical students. Bulletin of the Chuvash University. No. 3, 2010, pp. 98-102.

[15] Method of diagnosing the mental state of a person [Electronic resource]: application BY A20140678/ Mezianaya K, Karaneuski K, Yashin K.- Publ. date 30.08.2015.- Mode of access: https://belgospatent.by/files/Bulletin/Izob/2015/20154.pdf.- Date of access 2014.12.05.

[16] Glance S. Primer of Biostatistics. Medical Statistics. Moscow. Practica, 1998.

[17] Young K. How to Recognize the Signs of Internet Addiction and a Winning Strategy for Recovery. New York, Publisher Wiley, 1998. 